\title{
Anti-Trichomonas vaginalis Effect of Methanolic Extracts of Sambucus nigra in Comparison with Metronidazole
}

\author{
Ardavan Niknam ${ }^{1}$, Bahman Rahimi Esboei (iD ${ }^{2,{ }^{*}}$ and Aroona Chabra ${ }^{3}$ \\ ${ }^{1}$ Department of Microbiology, Jahrom Branche, Islamic Azad University, Jahrom, Iran \\ ${ }^{2}$ Department of Parasitology and Mycology, Faculty of Medicine, Tonekabon Branch, Islamic Azad University, Tonekabon, Iran \\ ${ }^{3}$ Department of Pharmacognosy, Faculty of Pharmacy, Islamic Azad University, Ayatollah Amoli Branch, Amol, Iran \\ "Corresponding author: Department of Parasitology and Mycology, Faculty of Medicine, Tonekabon Branch, Islamic Azad University, Tonekabon, Iran. Email: \\ bahman5164@yahoo.com
}

Received 2018 January 17; Revised 2018 July 18; Accepted 2018 December 23.

\begin{abstract}
Background: Trichomoniasis is the most common non-viral sexually transmitted disease caused by a flagellated protozoan living in the genitourinary tract, which infects both men and women. Metronidazole is the treatment of choice for trichomoniasis. Researchers are seeking an alternative to metronidazole because of its inevitable side effects and toxicity.

Objectives: This study aimed to evaluate the effect of the methanolic extract of Sambucus nigra against Trichomonas vaginalis in vitro. Methods: Plants were collected from different areas of Mazandaran Province, northern Iran. Fruits were separated, shade-dried, milled, and their methanolic extract was prepared in concentrations of 100, 200, 400, and $800 \mu \mathrm{g} / \mathrm{mL}$. Parasites were obtained from patients referring to different health centers of Mazandaran province, cultured in Dorset medium, and incubated at $37^{\circ} \mathrm{C}$. The effects were evaluated and compared to a control group. The data were analyzed by SPSS 18 using the ANOVA test.

Results: The exposure time and concentration of the extracts had a direct effect on anti-parasitic activity so that increasing extract concentration and incubation time heightened the anti-trichomoniasis effects. The concentrations of 400 and $800 \mu \mathrm{g} / \mathrm{ml}$ of the plant had 100\% efficacy after 72 and 48 hours, respectively.

Conclusions: It can be concluded from our results that the methanolic extract of S. nigra has a remarkable ability to destroy $T$. vaginalis and it can be considered an effective drug against $T$. vaginalis with further studies in human and animal models.
\end{abstract}

Keywords: Trichomonas vaginalis, Methanolic Extract, Sambucus nigra, Metronidazole

\section{Background}

Trichomoniasis is one of the most common nonviral sexually transmitted diseases (STDs), whose causative agent is a flagellated protozoan living in the genitourinary system called Trichomonas vaginalis (T. vaginalis). It can cause trichomoniasis in both men and women $(1,2)$. Trichomoniasis infection is more common in women and is associated with several clinical problems and symptoms, including awful smell vaginal discharge, painful urination, genital excitability, disorders after sexual intercourse, premature rupture of membranes, preterm birth, low birth weight, and increased risk of infection with HIV $(1,3-5)$. The worldwide studies and statistics indicate that in developed countries, a significant percentage (more than $50 \%$ ) of patients referring to STD clinics suffer from trichomoniasis, and the rate of infection is increasing $(6,7)$. Also, studies in our country have shown that Iran is the endemic focus of this infection $(5,8,9)$.

Metronidazole has been known as the gold standard treatment for trichomoniasis, which has a significant effect on the treatment of this disease (10). However, side effects such as nausea, vomiting, bad taste, gastrointestinal disorders, exanthem, urticaria, angioedema, vertigo, peripheral neuropathy, and transient neutropenia are observed with the use of this drug, which reduces the willingness to use it by the patients (10-12). Additionally, in recent years, the evidence of drug resistance to metronidazole has been reported in some studies, which could be another reason for research on alternative trichomoniasis treatment (13).

The use of medicinal herbs has been common in many countries around the world for many years. Today, the tendency to use them is increasing due to the benefits including fewer side effects, better access, cost-effectiveness, and adaptability of the physiological function of the body to their therapeutic effects $(14,15)$. Studies on the antiparasitic effects of plants, particularly against trichomoniasis, have been increasing in recent years, often accompa- 
nied by satisfactory results (16-18). For example, Yousefi et al. (19) conducted a study to investigate the effect of the hydroalcoholic extract of Peppermint and Salvia officinalis on T. vaginalis parasites, and found that the parasite did not grow at a concentration of $2 \mathrm{mg} / \mathrm{mL}$ of $S$. officinalis extract and $4 \mathrm{mg} / \mathrm{mL}$ of Peppermint extract (19). Also, Arefkhah et al. (20) conducted another study to investigate the effect of the hydroalcoholic extract of Scrophularia striata Boiss on $T$. vaginalis and concluded that this plant extract could completely inhibit the growth at a concentration of $4 \mathrm{mg} / \mathrm{mL}$, and the inhibition rate of parasite growth was 99\% at a concentration of $2 \mathrm{mg} / \mathrm{mL}(20)$. Besides, Sambucus spp., belonging to the Caprifoliaceae family, is known and used as an antiseptic, antiviral, antioxidant, anti-inflammatory, analgesic, and anti-proliferating agent due to the presence of eurosialic acid in its extract (21-23). Rahimi Esboei et al. (24) investigated the anti-parasitic effect of this plant against hydatid cyst protoscolex and Giardia lamblia cyst and observed an acceptable ability against this infection $(24,25)$.

\section{Objectives}

As there are no published documents on the antitrichomoniasis effects of $S$. nigra, the present study was conducted to evaluate the in-vitro anti-trichomoniasis effects of S. nigra in laboratory conditions.

\section{Methods}

\subsection{Plant Collection and Extraction}

The plant was collected from different regions of Mazandaran Province and was registered at the Faculty of Health of Mazandaran University of Medical Sciences after confirmation of the scientific name and plant herbarium with registration no. 137-95. The fruits of the plant were shade-dried and crushed by electric grinding, and the powders were stored in dark containers. Then, 500 mL of methanol (Merck, Germany) was added to the plant powder and placed in the laboratory for $48 \mathrm{~h}$. In the next step, the plant waste was separated and the solvent in the solution was evaporated under vacuum conditions by an evaporator. The dried powder was prepared at concentrations of 100, 200, 400, and $800 \mu \mathrm{g} / \mathrm{mL}$, and used for antiparasitic evaluation (24).

\subsection{Preparation and Culture of Trichomonas vaginalis Parasite in Culture Medium}

Vaginal samples were gathered by using sterile cotton swabs. Direct examinations were undertaken microscopically and then cultures were done in Dorset culture media. All test tubes were incubated at $37^{\circ} \mathrm{C}$ for eight days and microscopic observations were done every two days. The genus and species of the parasite were confirmed by morphological and morphometric methods. In this study, $5 \times$ $10^{5}$ parasites were used for each reaction. Metronidazole as positive control and dimethyl sulfoxide (DMSO) as negative control were also used in this study (26).

\subsection{Investigation of the Anti-Parasitic Effect of Sambucus nigra}

This study was carried out by a 24-well cell culture plate. In this test, $5 \times 10^{5}$ parasites of $T$. vaginalis were added to each well and $100 \mu \mathrm{L}$ of different concentrations of herbal extracts were added, as well. The plate was placed in an incubator at $37^{\circ} \mathrm{C}$, and the viability percentage of the parasite was evaluated at $12,24,48$, and $72 \mathrm{~h}$ intervals using the microscopic method. Besides, $1 \%$ trypan blue was used for each concentration, as well as positive and negative control groups, and the growth inhibition was calculated using the following formula (27):

$\% G I=\left(1-\frac{G R_{\text {extract }}}{G R_{\text {control }}}\right) 100$

Finally, the number of parasites was counted at certain times using Neubauer slides and the minimum inhibitory concentration $\left(\mathrm{IC}_{50}\right)$ was calculated.

\subsection{Statistical Analysis}

The experiments were conducted in triplicate. Finally, the obtained data were analyzed using SPSS software with the chi-square test.

\section{Results}

This study was carried out using the methanolic extract of the plant to evaluate its anti-trichomoniasis effects at concentrations of $100,200,400$, and $800 \mu \mathrm{g} / \mathrm{mL}$ at exposure times of $12,24,48$, and $72 \mathrm{~h}$. The results are shown in Table 1 and Figure 1 . As observed, the acceptable efficacy of plant extract against T. vaginalis was observed at concentrations of 400 and $800 \mu \mathrm{g} / \mathrm{mL}$. It is also noticeable that the effect of the extract had a direct relationship with exposure time, implying that the inhibition of parasite growth enhanced with increasing exposure time. In addition, the best inhibitory effect on parasite growth was observed at an extract concentration of $800 \mu \mathrm{g} / \mathrm{mL}$. At this concentration, the anti-trichomoniasis effect of the extract was equal to the anti-trichomoniasis effect of metronidazole (as an anti-trichomoniasis standard drug). The inhibition rate of parasite growth was not significant in a negative control environment (Table 2). 


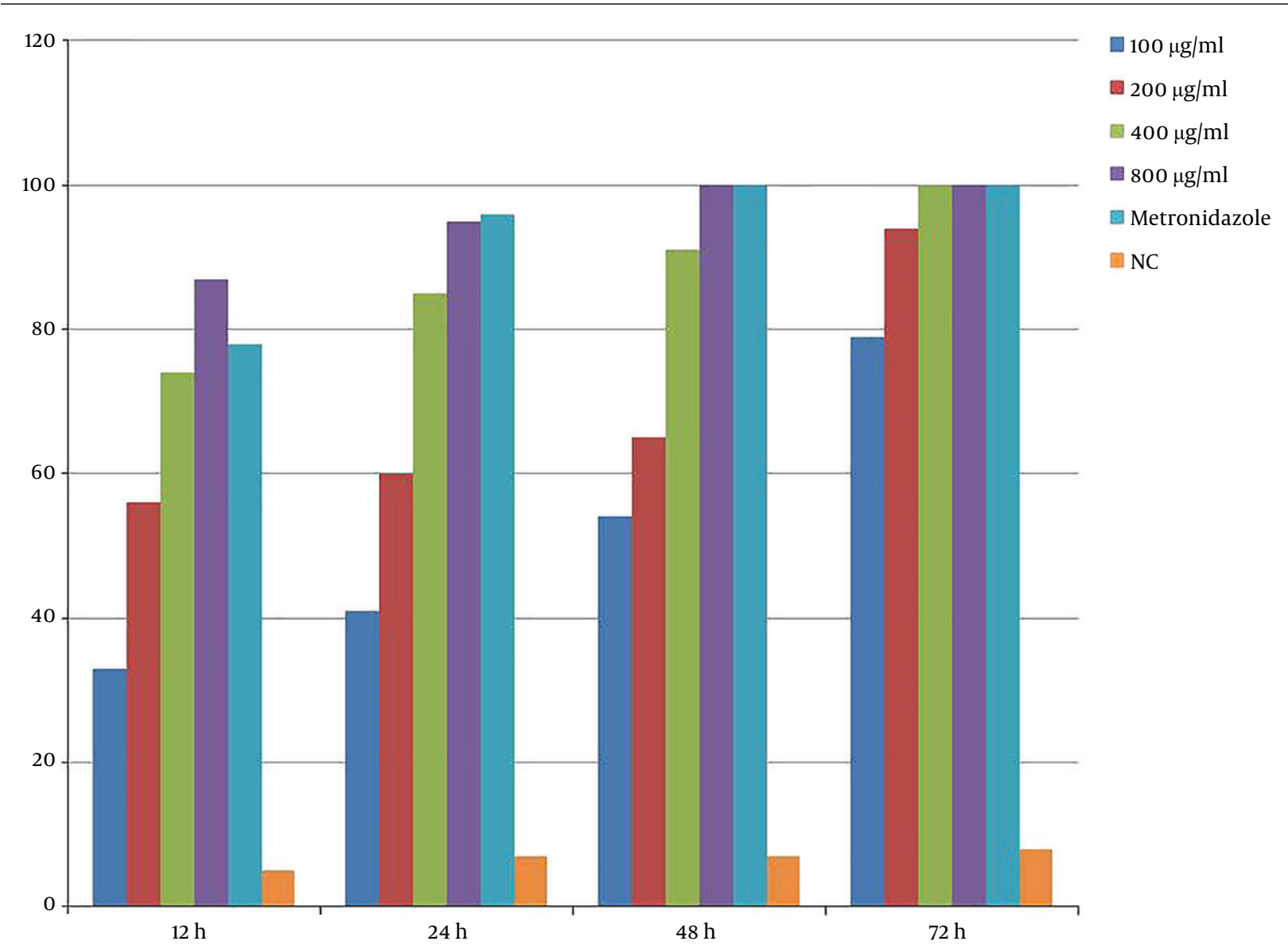

Figure 1. Growth inhibitory effect of the methanolic extract of Sambucus nigra at concentrations of 100, 200, 400, and 800 $\mu \mathrm{g} / \mathrm{mL}$ against Trichomonas vaginalis after $12,24,48$, and $72 \mathrm{~h}$ compared to the positive control (metronidazole) and negative control (medium with DMSO).

Table 1. Growth Inhibitory Effect of the Methanolic Extract of Sambucus nigra at Concentrations of 100, 200, 400, and 800 $\mu \mathrm{g} / \mathrm{mL}$ Against Trichomonas vaginalis After 12, 24, 48, and $72 \mathrm{~h}$ Compared to the Positive Control (Metronidazole) and Negative Control (Medium with DMSO).

\begin{tabular}{|c|c|c|c|c|c|c|c|}
\hline Concentration & $100 \mu \mathrm{g} / \mathrm{mL}$ & $200 \mu \mathrm{g} / \mathbf{m L}$ & $400 \mu \mathrm{g} / \mathrm{mL}$ & $800 \mu \mathrm{g} / \mathrm{mL}$ & NC & Metronidazole & Pvalue \\
\hline 12 hours & 33 & 56 & 74 & 87 & 5 & 78 & 0.031 \\
\hline 24 hours & 41 & 60 & 85 & 95 & 7 & 96 & 0.011 \\
\hline 48 hours & 54 & 65 & 91 & 100 & 7 & 100 & 0.000 \\
\hline 72 hours & 79 & 94 & 100 & 100 & 8 & 100 & 0.000 \\
\hline
\end{tabular}

Abbreviatiom: NC, negative control (DMSO).

\section{Discussion}

Based on the results, the methanolic extract of S. nigra significantly decreased the number of Trichomonas parasites at different times. The antiparasitic effect of the plant extract increased with its concentrations from 100 to 800 $\mathrm{mg} / \mathrm{L}$, and the best results were observed at $800 \mu \mathrm{g} / \mathrm{mL}$, which was equal to the efficacy of metronidazole. Also, the time was effective on the effect of the plant extract on the parasite so that the highest efficacy was observed at the highest exposure time for each concentration.

Although there is an effective drug against this disease, consumers have complaints and are not satisfied, and drug resistance has led to conducting various studies for finding new drugs (15). Medicinal herbs have become one of the most attractive options in recent years to achieve effective drugs with lower side effects against 
Table 2. Minimum Inhibitory Concentration $\left(\mathrm{IC}_{50}\right)$ of Methanolic Extract of Sambucus nigra at Concentrations of 100, 200, 400, and $800 \mu \mathrm{g} / \mathrm{mL}$ Against Trichomonas vaginalis After 12, 24, 48 and $72 \mathrm{~h}$

\begin{tabular}{lc}
\hline Time & Minimum Inhibitory Concentration $\left(\mathbf{I C}_{\mathbf{5 0}}\right), \mu \mathbf{g} / \mathbf{m L}$ \\
\hline $\mathbf{1 2}$ hours & 151.15 \\
\hline $\mathbf{2 4}$ hours & 121.95 \\
\hline $\mathbf{4 8}$ hours & 92.59 \\
$\mathbf{7 2}$ hours & 63.29 \\
\hline
\end{tabular}

all types of pathogens (17). Many studies are annually carried out in Iran and other parts of the world to investigate the ability of these types of plants against pathogenic agents (28). The use of herbal medicines and studies on the anti-parasitic properties of herbs against trichomoniasis have been also taken into consideration (17). Sambucus nigra is known as an antiseptic, antiviral, antioxidant, anti-inflammatory, analgesic, and antiproliferative agent due to the presence of eurosialic acid in its extract. Anthocyanins, especially cyanidin 3-sambubioside and cyanidin 3-glucoside, are polyphenolic compounds responsible for anti-oxidative effects (29), with antibacterial, antiviral, and anti-allergic effects, as well as immune-stimulating properties in humans (30-32).

Uncini Manganelli et al. showed the antiviral activity of S. nigra in the contradiction of the feline immunodeficiency virus using feline kidney Crandell cells. In another study, Razi Jalali et al. (33) used this plant to evaluate its anti-parasitic effect against hydatid cyst in an in vivo study and observed the acceptable ability of the plant against this infection. Their results indicated that in all infected groups, the number, size, and volume of cysts were significantly lower in the test groups than in the control group ( $\mathrm{P}<0.05$ ) (33). Daryani et al. (23) reported that the fruit extract of S. nigra at concentrations of 5, 10, 25, and $50 \mathrm{mg} / \mathrm{mL}$ was effective against Toxoplasma gondii in an in vitro study. The concentrations used in this study were significantly lower than those in other work. In the current work, $100 \%$ efficacy was observed at a concentration of $400 \mu \mathrm{g} / \mathrm{ml}$ after 48 hours of incubation. Given the research done, as well as the presence of effective compounds such as anthocyanins and eurosialic acid, it is expected that more research is done on this plant (22).

In the current work, the methanolic extract of S. nigra was used to evaluate its anti-trichomonas activity and our results indicated that this plant was fully effective. Up to now, several plants have been used; but, there has not been any success in the production of medication. Ferula szowitsiana (34), Artemisia, Zataria, Myrtus (35), Freula assafoetida, Allium sativum (36), Taxus baccata (37), Saponaria officinalis (16), and many others plants have shown a variety of ef- fects. Although many studies have been carried out and many plants have been studied, research on finding an effective plant remains ongoing. The comparison of our results with the results of the above-mentioned studies illustrates that the methanolic extract of S. nigra was very effective in removing $T$. vaginalis.

\subsection{Conclusions}

In our study, the exposure time for complete parasite removal was detected to be lower than in previous studies. Moreover, it was found that the methanolic extract of S. nigra was equal in effectiveness to metronidazole against $T$. vaginalis, which indicates the high potential of this plant to be examined as a drug candidate for the treatment of trichomoniasis. The results confirmed the potential of S. nigra against $T$. vaginalis and showed that, by supplementary studies on the effects of this plant, it can be considered a good alternative to metronidazole. It is suggested that animal and human models be used to study the effect of this plant on the growth and amplification of T. vaginalis.

\section{Acknowledgments}

We would like to express our sincere gratitude to all staff of the Microbiology Laboratory at the Islamic Azad University, Jahrom Branche.

\section{Footnotes}

Authors' Contribution: None declared by the authors. Conflict of Interests: The authors report no conflicts of interest in this work.

Funding/Support: None declared by the authors.

\section{References}

1. Hainer BL, Gibson MV. Vaginitis: diagnosis and treatment. Am Fam Physic. 2011;83(7):807-15.

2. Kissinger P, Adamski A. Trichomoniasis and HIV interactions: a review. Sex Transm Infect. 2013;89(6):426-33. doi: 10.1136/sextrans-2012051005. [PubMed: 23605851]. [PubMed Central: PMC3748151].

3. Hirt RP, Sherrard J. Trichomonas vaginalis origins, molecular pathobiology and clinical considerations. Curr Opin Infect Dis. 2015;28(1):729. doi: 10.1097/QCO.0000000000000128. [PubMed: 25485651].

4. Wolner-Hanssen P, Krieger JN, Stevens CE, Kiviat NB, Koutsky L, Critchlow $\mathrm{C}$, et al. Clinical manifestations of vaginal trichomoniasis. JAMA. 1989;261(4):571-6. doi: 10.1001/jama.1989.03420040109029. [PubMed: 2783346].

5. Akbari Z, Matini M. The study of trichomoniasis in pregnantwomen attending hamadan city health centers in 2015. Avicenna J Clin Microbiol Infect. 2017.

6. Hook E3. Trichomonas vaginalis-no longer a minor STD. Sex Transm Dis. 1999;26(7):388-9. doi: 10.1097/00007435-199908000-00004. [PubMed: 10458631]. 
7. Workowski KA, Bolan GA. Sexually transmitted diseases treatment guidelines (2015). Reprod Biol Endocrinol. 2015;24:51-6. doi: 10.1186/s12958-015-0023-2. [PubMed: 25889494]. [PubMed Central: PMC4397678].

8. Mazloumi GA, Namazi A, Ghazanchaei A, Alizadeh S, Sehati F, Rostamizadeh S, et al. Prevalence and risk factors of trichomoniasis among women in Tabriz. Arch Clin Infect Dis. 2008;3(2).

9. Hezarjaribi HZ, Fakhar M, Shokri A, Teshnizi SH, Sadough A, Taghavi M. Trichomonas vaginalis infection among Iranian general population of women: a systematic review and meta-analysis. Parasitol Res. 2015;114(4):1291-300. doi: 10.1007/s00436-015-4393-3. [PubMed: 25732256].

10. Cudmore SL, Delgaty KL, Hayward-McClelland SF, Petrin DP, Garber GE. Treatment of infections caused by metronidazole-resistant Trichomonas vaginalis. Clin Microbiol Rev. 2004;17(4):783-93. table of contents. doi: 10.1128/CMR.17.4.783-793.2004. [PubMed: 15489348]. [PubMed Central: PMC523556].

11. Klebanoff MA, Carey JC, Hauth JC, Hillier SL, Nugent RP, Thom EA, et al. Failure of metronidazole to prevent preterm delivery among pregnant women with asymptomatic Trichomonas vaginalis infection. $N$ Engl J Med. 2001;345(7):487-93. doi: 10.1056/NEJMoa003329. [PubMed: 11519502].

12. Bouchemal K, Bories C, Loiseau PM. Strategies for Prevention and Treatment of Trichomonas vaginalis Infections. Clin Microbiol Rev. 2017;30(3):811-25. doi: 10.1128/CMR.00109-16. [PubMed: 28539504]. [PubMed Central: PMC5475227].

13. Smith JD, Cudmore SL, Garber GE. Diagnosis and Treatment of Metronidazole-Resistant Trichomonas vaginalis Infection. Antimicrob Drug Resist. 2017. p. 1277-91. doi:10.1007/978-3-319-47266-9_28.

14. Ramirez-Moreno E, Soto-Sanchez J, Rivera G, Marchat LA. Mexican Medicinal Plants as an Alternative for the Development of New Compounds Against Protozoan Parasites. Natural Remedies in the Fight Against Parasites. 2017. doi: 10.5772/67259.

15. Artimani T, Shabanian S, Heidari-Soureshjani S, Asadi-Samani M, Luther T. A review of iranian medicinal plants with teratogenic and abortion-inducing side effects. Int J Pharm Sci Res. 2017;8(6):2372-7.

16. Ziaei Hezarjaribi H, Momeni Z, Azadbakht M, Rahimi Esboei B, Fakhar M, Akbarian M. Effects of hydroalcoholic extract of Saponaria officinalis leaf on growth of Trichomonas vaginalis in vitro. J Mazandaran Univ Med Sci. 2016;25(134):52-9.

17. Calzada F, Yepez-Mulia L, Tapia-Contreras A. Effect of Mexican medicinal plant used to treat trichomoniasis on Trichomonas vaginalis trophozoites. J Ethnopharmacol. 2007;113(2):248-51. doi: 10.1016/j.jep.2007.06.001. [PubMed:17628366].

18. Mehriardestani M, Aliahmadi A, Toliat T, Rahimi R. Medicinal plants and their isolated compounds showing anti-Trichomonas vaginalis- activity. Biomed Pharmacother. 2017;88:885-93. doi: 10.1016/j.biopha.2017.01.149. [PubMed: 28178618].

19. Yousefi M, Taghipur S, Arefkhah N, Rahimian R, Davoudian A, RafieianKopaei M. In-vitro effect of menthe piperita and salvia officinalis extracts on trichomonas vaginalis. J Isfahan Med Sch. 2013;31(240):811-8.

20. Arefkhah N, Taghipur S, Yousefi M, Rafieian-Kopaei M, Daneshpur S In-vitro effect of hydro-alcoholic extract of Tanacetum parthenium extract on Trichomonas vaginalis. J Isfahan Med Sch. 2013;31(236).

21. Veberic R, Jakopic J, Stampar F, Schmitzer V. European elderberry (Sambucus nigra L.) rich in sugars, organic acids, anthocyanins and selected polyphenols. Food Chem. 2009;114(2):511-5. doi: 10.1016/j.foodchem.2008.09.080.

22. Lee J, Finn CE. Anthocyanins and other polyphenolics in American el- derberry (Sambucus canadensis) and European elderberry (S. nigra) cultivars. J Sci Food Agric. 2007;87(14):2665-75. doi: 10.1002/jsfa.3029. [PubMed: 20836175].

23. Daryani A, Ebrahimzadeh MA, Sharif M, Ahmadpour E, Edalatian $S$, Rahimi Esboei B, et al. Actividad anti-Toxoplasma de extractos metanólicos de frutos y hojas de Sambucus nigra (Caprifoliaceae). Revista Biol Trop. 2015;63(1). doi: 10.15517/rbt.v63i1.14545.

24. Rahimi-Esboei B, Ebrahimzadeh MA, Gholami SH, Falah-Omrani V. Anti-giardial activity of Sambucus ebulus. Eur Rev Med Pharmacol Sci. 2013;17(15):2047-50.

25. Gholami SH, Rahimi-Esboei B, Ebrahimzadeh MA, Pourhajibagher M. In vitro effect of Sambucus ebulus on scolices of Hydatid cysts. Eur Rev Med Pharmacol Sci. 2013;17(13):1760-5. [PubMed: 23852900].

26. Badparva E, Ali PO, Kheirandish F, Pornia Y, Azizi M. Sensitivity assessment of direct method for diagnosis of Trichomonas vaginalis in comparison with Dorset Culture media. YAFTEH. 2010;12(1):25-30.

27. Vazini H, Esboei BR. In vitro study of the effect of hydroalcholic extracts of Carum copticum and Ferula asafetida against Trichomonas vaginalis. Sci J Kurdistan Univ Med Sci. 2018;23(1).

28. Bonjar S. Evaluation of antibacterial properties of some medicinal plants used in Iran. J Ethnopharmacol. 2004;94(2-3):301-5. doi: 10.1016/j.jep.2004.06.007. [PubMed: 15325735].

29. Dawidowicz AL, Wianowska D, Baraniak B. The antioxidant properties of alcoholic extracts from Sambucus nigra L. (antioxidant properties of extracts). LWT Food Sci Technol. 2006;39(3):308-15. doi: 10.1016/j.lwt.2005.01.005.

30. Würth K, Bonerz D, Will F, Patz C, Quast P, Hillebrand S, et al. Anthocyanalterung in Säften und Konzentraten der schwarzen Johannisbeere-Teil 1: Kinetik der Abnahme von Anthocyanen bei der Lagerung. Deut Lebensm-Rundsch. 2009;105:176-82.

31. Brambilla A, Lo Scalzo R, Bertolo G, Torreggiani D. Steam-blanched highbush blueberry (Vaccinium corymbosum L.) juice: phenolic profile and antioxidant capacity in relation to cultivar selection. $J$ Agric Food Chem. 2008;56(8):2643-8. doi: 10.1021/jf0731191. [PubMed: 18370394].

32. Nakajima JI, Tanaka I, Seo S, Yamazaki M, Saito K. LC/PDA/ESIMS Profiling and Radical Scavenging Activity of Anthocyanins in Various Berries. J Biomed Biotechnol. 2004;2004(5):241-7. doi: 10.1155/S1110724304404045. [PubMed: 15577184]. [PubMed Central: PMC1082896].

33. Razi Jalali M, Alborzi A, Najafzade VH, Ghorbanpour M, Derakhshan L. Survey on effects of albendazole, Echinacea purpurea, sambucus ebulus and zinc oxide nanoparticles on unilocular hydatid cyst in mice. Sci Res Iran Vet J. 2015;11(2):68-125.

34. Khanmohammadi M, Ganji S, Reyhani Rad S. Anti-protozoan Effects of Methanol Extracts of the Ferula szowitsiana on the Trichomonas Vaginalis Trophozoites in vitro. Int JWomen's Health Reprod Sci. 2014;2(5):301-6. doi: 10.15296/ijwhr.2014.49.

35. Azadbakht M, Ziai H, Abdollahi F, Shabankhani B. Effect of essential oils of Artemisia. Zataria and Myrtus on Trichomonas vaginalis.J Med Plant. 2003;4(8):35-40.

36. Sarkari B, Tadayon H, ASKARIAN SH, Farnia E, Askarian M. In Vitro antiTrichomonas activity of Freula assafoetida and garlic extracts. J Gorgan Univ Med Sci. 2009;11(31):13-7.

37. Sharafi SM, Yousefi M, Yousefi HA, Asghari G, Darani HY. In vitro effects of various plants extracts on the growth of Trichomonas vaginalis. Infect Disord Drug Targets. 2013;13(5):322-7. doi: 10.2174/1871526514666140321111329. [PubMed: 24712672]. 